\title{
Gender Differences in Anthropometric Indices Among Primary School Children in Delta South-Senatorial District, Delta State Nigeria
}

\author{
Ogbe Joseph Ogheneruese ${ }^{1}$, Ekuremu Joy ${ }^{2}$ \\ ${ }^{1}$ Department of Physical and Health Education, Delta State University, Abraka, Delta State, Nigeria \\ ${ }^{2}$ Ministry of Health, Delta State Primary Health Agency, Asaba, Delta State, Nigeria
}

Email address:

Ogbe_Joseph@yahoo.com (O.J. Ogheneruese)

To cite this article:

Ogbe Joseph Ogheneruese, Ekuremu Joy. Gender Differences in Anthropometric Indices Among Primary School Children in Delta SouthSenatorial District, Delta State Nigeria. International Journal of Nutrition and Food Sciences. Vol. 5, No. 3, 2016, pp. $220-223$. doi: $10.11648 /$ j.ijnfs.20160503.20

Received: January 13, 2016; Accepted: February 17, 2016; Published: May 17, 2016

\begin{abstract}
Purpose: the purpose of this study was to assess gender differences in anthropometrics of weight, height, body mass index (BMI) and mid upper-arm-circumference. Method: the method was the exploratory study design. The sampled population was 510 primary school children between the ages of $6-12$ years obtained by multi-stage sampling techniques along with simple ballot method. Two research questions and one hypothesis guided the study. Data were obtained through the use of weighing bathroom scale, standiometer, tape and calculating BMI from $\mathrm{wt}(\mathrm{kg}) / \mathrm{ht}(\mathrm{m})^{2}$. Findings: there was no significant difference between weight and reference standard weight; between height and reference standard height; between muac and reference standard muac. It was found that boys have advantage over girls in weight, body mass index and mid upper-arm-circumference, while height was equal in both genders. There was no significant difference in weight and reference standard weight, in height and reference standard height except in bmi and reference standard bmi. It was found that gender anthropometric was not significantly different from the international reference standard. It was evident from this study that there was no gender difference in anthropometric measures among children in this study. Recommendation: it was recommended that the present nutritional status of children be maintained and regular growth monitoring of children as health surveillance as to maintain the status and detect early warning signs, among others.
\end{abstract}

Keywords: Anthropometric, Gender, Health, Nutritional, Children, Delta - Nigeria

\section{Introduction}

Health surveillance is an important organ of public/community health. It brings to focus the health situation in a community, thereby eliciting intervention if need be. One of such issue of surveillance is nutrition especially in children. The growth of children when compared to WHO (2000) reference standard is used as judgment to determine the state of children in a community, state or nation. Growth is monitored by anthropometrics indices. Anthropometrics measure weight (wt), height (ht), body mass index (BMI), midupper arm circumference, head circumference, skin fold among others. These human body indices spelt out the state of growth of an individual and the community. According to Cogil (2003) "Anthropometry can be used for various purposes, with interest on parameter(s) be determined, for example BMI can used to detect obesity in adult as BMI of 30 or higher is considered obese (Centre for Disease Control and Prevention 2006). Measurement of height and weight from which BMI can be calculated reveals stunted growth (low height for age) or growth failure (Cogil 2003). Cogil (2003) stated likewise that weight-for-height helps to identify children suffering from current or acute under-nutrition or wasting while height-for-age identifies past under-nutrition. The author stated further that weight-for-age identifies the condition of being underweight for a specific age. Health status is a reflection of nutrition and level of infection specially in children. These can be assessed by anthropometric measure in individual and community surveys. Children in primary school within the ages of $6-12$ years were chosen for this study 
because they are the most vulnerable group in the society due to nutrition and infections yet they remain the leaders of tomorrow. Their growth, development and intellectual standing reflects society of tomorrow. The choice of primary school children become the option as most children of the age of 6 12years are expected to be in school. Anthropometric indices are not the same all over the world. There is difference based on climatic changes, nutrition, genetics, social-economic class and gender.

Significant differences does not exist between males and females of the same age on the anthropometrics indices (National Centre for Chronic Diseases Prevention and Health Promotion (2000). But social opportunities varies between baby boy and the baby girl in developing countries in terms of socialization and educational opportunities (Alafiatayo 2012). Many studies in Nigeria suggest variation between males and females on their body measures (Hefia, Ibrahim \& Atiku 2012, Alwokoro, Ifada, Qnochel \& Olomu, 2006 Yunusa, Atiku \& Abubakar, 2011). Hence there is the need to study the anthropometry of males and females primary school children as to close the gap of dearth of information on their growth, status ass nutrition and health surveillance in South-Senatorial District, Delta State.

The focus of the study were males and females anthropometric indices of weight (wt), height (ht), Body Mass Index (BMI), and Mid-upper-arm circumferences (MUAC) being compared to international standard (National Centre for Chronic Diseases Prevention and Health Promotion 2000). The study was a community health surveillance meant to understand the growth of children in Delta South Senatorial District, Delta State, Nigeria in comparison to international standard and by so doing introduce intervention if need be or campaign for improved nutrition or campaign to sustain standard. The purpose was to determine the weight, height, Body Mass Index and upper mid-arm circumference of children and compare to international anthropometric standard. The study will be of benefit to health educators in their campaign for improved nutrition, improved health and reduction in infant and child mortality among others.

\section{Conceptual Framework}

The study was hinged on the believe that anthropometric indicators reveals the status of nutritional health of individual and community especially in infant and children. Drawing from the presentation of Cogril (2003); "Well chosen and reported monitoring indicators will enhance programme management and can provide valuable insight into trends of anthropometric indicators used for determining impact. The recommended annual monitoring indicates for maternal and child health and nutrition are percentage of eligible children in growth monitoring and promotion (GMP) percentage of children in GMP programme gaining weight in the past 3 months (Gender specific)".

From the conceptual framework, it was understood that knowledge of children growth index is a necessary surveillance for reducing infant and child morbidity and mortality.

\section{Research Questions}

To guide this study, two research questions and one hypothesis was postulated;

1. What is the mean anthropometry indices (wt, ht, bmi and muac) of male and female primary school children between the ages of $6-12$ years in South Senatorial District, Delta State.

2. To what extent do differences exist between genders in primary school children between the ages of 6 12 years in Delta South-Senatorial District, Delta State.

\section{Hypothesis}

Gender will not be significantly different among primary school children between the ages of $6-12$ years in their anthropometric indices (wt, ht, BMI and muac) in DeltaSouth-senatorial Districts, Delta State, Nigeria when compared to international reference standard (WHO 2000).

\section{Review}

Studies have been carried out on anthropometrics on gender comparison. Amutaand Homsou (2009) found in their study that mean height of girls was higher than boys as compared to the same age. Amuta and Houmsou (2009) found that boys have higher BMI than girls. Jaswal, Grewal, Vig and Gulati (2003) found in their study that no male was malnourished when compared to international standard but this was not the case of the females. In another study, Hafiz, Ibrahim and Atiku (2012) had higher mean scores of BMI for males than females $(18.23 \pm 1.76$ and $17.30 \pm 3.2$ respectively). Nwokoro, Ifada, Onochei and Olomu (2006) also found in their study that males were advantageous over females in their BMI. Yunusa, Atikuand Abubakar (2011) also found same in their study. In another study, Goon, Toriola, Amuisa, Monyeki, Akinyemi and Alabi (2001) found that gender wise, girls with $75.0 \%$ and boys with $78 \%$ fell within the grade I, thinness category base WHO classification of severe malnutrition. Amosu, Degun, Atulomah and Olanrewju (2011) observed in their study that there is no significant difference in weight, height and midupper hand circumference in children between the ages of 6 and 59months in Ipokia Local Government of Ogun State Nigeria.

\section{Method and Material}

The same method and material was used in a serialized study Ogbe and Ekuremu (2016A)]. The study adopted the exploratory research design. The population was 30,387 primary school children in Delta South-Senatorial District Delta State, Nigeria (Ministry of Education, Asaba 2010). The sample size was 480 . This was adjudged to be adequate based on Areoye (2004) assertion that a sample of 384 is 
adequate for a study of 10,000 and above population. The multi-stage sampling technique, and the simple ballot techniques were used to sort the sample. Ten percent $(10 \%)$ of the schools in each Local Government Area of the Senatorial District were sampled. The Senatorial District is made up of 8 local Government Areas. Thus 34 primary schools were sampled, by systematic sampling technique. Ten percent $(10 \%)$ of the classes in each school were sampled with systematic sampling technique producing a total of 48 classes. From each class, $10 \%$ of the pupils were sampled using the classroom register under systematic sampling technique. A total of 510 children were sampled. The study took from January $6^{\text {th }}-2013$ - March $10^{\text {th }} 2014$.

The research instruments were:

- Human measuring scale in metric and linear measurement

- Stadiometer; Calibrated in metric and linear

- Colour strips arm circumference measure designed in metric.

Measure of weight was taken on the scale with the pupils wearing light clothing. The weight of the light cloths were subtracted from the weight and recorded with a pencil on a paper. To obtain the height pupils were made to stand on the stadiometer without a footwear with theoccipital of the head resting on the stadiometer with face prone forward. Reading was taken with a foot measure on the head reaching the measure and reading taken to the next millimeter and recorded on a paper with pencil. The mid-upper-arm circumference was taken with an arm circumference colour strip in metric reading. The BMI was calculated based on high/(wt $)^{2}$.

Validity and reliability of the research instrument was obtained with a first and second reading of each measurement for 60 children between the ages of 6-12 years. Both first and second measures were compared and found not to have much difference. The reliability was obtained using the validity readings of 60 children of the study age in Abraka, outside the study area. Data obtained were calculated for technical error of measurement (TEM) and reliability. The reliability was obtained through the technical error of measurement as presented;

Wt Ht BMI

TEM 0.090.990.16

Reliability 0.990.900.96

Data were collected through the school Headmasters between January $6^{\text {th }} 2013$ - March $10^{\text {th }}$ 2014. Data were analyzed using means and standard deviation and one-way analysis of variance (Anova) statistics.

\section{Findings}

Two hundred and sixty (260) male and two hundred and fifty (250) female children between the ages of $6-12$ years participated in the study.

Table 1 reveals that primary school children between the ages of $6-12$ years has mean weight of $19.19 \pm 3.86$ for males while mean weight for females was $18.98 \pm .86$ when compared to international standard mean of 23.13. Males had a mean height of $1.23 \pm .11$, for males while mean height of females was $1.22 \pm .11$ as compared to international standard mean of 1.21 and mean, mid upper arm circumference (MUAC) of $19.16 \pm 3.86$ for males and for females 18.98 \pm .862 as compared to international standard mean of 14.70 . Males has body mass index (BMI) of $15.16 \pm .76$ for males and for females it was $15.00 \pm .755$ as compared to international standard mean of 18.28 .

Table 1. Descriptive statistics of anthropometric indices of participants and the internationalReference standard (WHO 2000).

\begin{tabular}{llllll}
\hline & GENDER & INT STD & N & MEAN & STD DEV \\
\hline \multirow{6}{*}{ Weight } & Male & 23.13 & 260 & 19.19 & 3.86 \\
& Female & & 250 & 18.98 & .86 \\
& Total & & 510 & 19.08 & 2.82 \\
& Male & 1.21 & 260 & 1.23 & .11 \\
& Female & & 250 & 1.23 & .12 \\
& Total & & 510 & 1.23 & .11 \\
& Male & 14.70 & 260 & 15.16 & .76 \\
& Female & & 250 & 14.00 & .76 \\
& Total & & 510 & 15.08 & .76 \\
& Male & 18.27 & 260 & 19.19 & 3.86 \\
& Female & & 250 & 18.98 & .86 \\
& Total & & 510 & 19.08 & 2.82 \\
\hline
\end{tabular}

Table 2. One-way Anova Statistics of anthropometric indices of participants as compared to international standard.

\begin{tabular}{|c|c|c|c|c|c|c|}
\hline & $\begin{array}{l}\text { Sum of } \\
\text { square }\end{array}$ & Df & $\begin{array}{l}\text { Mean } \\
\text { square }\end{array}$ & $\mathbf{F}$ & Sig. & Remark \\
\hline \multicolumn{7}{|l|}{ Std wt } \\
\hline Between Groups & .10 & 1 & .10 & .01 & .95 & NS \\
\hline Within Groups & 13222.10 & 508 & 26.02 & & & \\
\hline Total & 13222.20 & 509 & & & & \\
\hline \multicolumn{7}{|l|}{ Std ht } \\
\hline Between Groups & .004 & 1 & .01 & .31 & .58 & NS \\
\hline $\begin{array}{l}\text { Within Groups } \\
\text { total }\end{array}$ & 6.26 & 508 & .01 & & & \\
\hline Total & 6.26 & 509 & & & & \\
\hline \multicolumn{7}{|l|}{ Std bmi } \\
\hline Between Groups & 3.27 & 1 & 3.27 & 5.71 & .02 & $\mathrm{SN}$ \\
\hline Within Groups & 290.97 & 508 & .57 & & & \\
\hline Total & 294.24 & 509 & & & & \\
\hline \multicolumn{7}{|l|}{ Std mauc } \\
\hline Between Groups & 5.52 & 1 & 5.52 & .69 & .41 & NS \\
\hline Within Groups & 4047.50 & 508 & 7.97 & & & \\
\hline Total & 4053.02 & 509 & & & & \\
\hline
\end{tabular}

Table 2 revealed that there was no significant difference between gender in their anthropometric measures of weight, height and mid-upper arm circumference. Body mass index was significant different with F- value of 5.71 and alpha of 0.02 .

\section{Discussion}

This study assessed anthropometric measures of children of the ages 6-12 years in Delta South Senatorial District, Delta State, Nigeria. It was found that Gender difference does not exist in weight, height and mid-upper arm circumference. In response to research question 1, it was found that similarity exist between gender in their wt, ht, bmi and muac 
(see table 1). In response to research question 2, it was found that males have advantage of $.21 \mathrm{in} \mathrm{wt,} .01 \mathrm{in} \mathrm{ht,} .26 \mathrm{in}$ bmiand .21 in mauc over their females counterpart. This could not be said to be significant as the differences fall below 0.05 alpha. (see table 1).

When the data were subjected to a one-way-Anova Statistics, it was observed that there was no significant difference in weight, height, mid-upper arm circumference between Gender. This finding was supported by that of Amuta and Houmsou (2009) who found that boys were slightly taller than girls. This finding was also supported by that of Amosu, Degun, Atulomah and Olarawanju (2011) found no significant difference in anthropometric indices of under 5 children between the ages of $6-59$ months in Ipokia local government of Ogun State, Nigeria. This finding correlated that of Nwokoro, Ifeda, Onochei and Olomu (2006) and Amuta and Houmsou s(2009) who also found a significant difference between boys and girls in their body mass index. (See table 2).

In this study, international standard anthropometric of wt, ht, BMI and Muac were used as the dependent variable. Thus it was found that gender was not significantly different with the international reference standard anthropometric (WHO 2000). Thus, it was revealed from this study that primary school children of the age $6-12$ years favorably fit with their international counterpart. Except in body mass index where significant difference was found between Gender in comparison to their international counterpart. These findings correlate the finding of Jaswel Grewal, Vig and Gulati (2003) who found that India children were found to be anthropometrically balance when compared to the standard of India Centre for medical research. Findings of this study did not show significant difference between the international standard reference (WHO 2000) in the three assessed anthropometric of weight, height and upper mid arm circumference except for body mass index where significant difference was recorded. The finding goes to show by implication that children in Delta-South Senatorial District, Delta State, Nigeria are healthy and by further implication were well fed and nourished children.

\section{Conclusion}

This study has shown that boys of the ages 6-12 years in Delta-South Senatorial District, Delta State, Nigeria were healthy and grows within the international status of children who fall within the accepted standard. It was evidence from this study that there was no gender difference in anthropometric measure among children in this study. Primary school children of the ages $6-12$ years in this part of the world were not different in their anthropometric indices when compared to the international reference standard (WHO 2000).

\section{Recommendations}

Arising from the findings of this study, it was recommended that;

1. The present nutritional status of children be maintain.

2. There should be regular growth monitoring of children as health surveillance as to maintain the status-quo of children growth and health as to detect early warning sign.

3. Issues associated with improved children's health such as immunization and avoidance of diarrhea be promoted as to maintain children health status.

4. Health education for health promotion be a continuous programme for parents as to appreciate the good growth and health of children.

\section{References}

[1] Amosu A. M, Degun A. M, Atulomah N. O. S \& Olanrewju (2011). A study of the Nutritional status of under 5 children of low-income earners in a South - Western Nigeria Community Current Research Journal of Biological Sciences 3 (6): 578585 .

[2] Amuta, E. U. \& Houmson, R. S. (2009). Assessment of nutritional status of children in Makurdi, Benue state. Pakistan Journal of Nutrition, 8: 169-694. DOI: 10.3923/pjn 2009. 691.694.

[3] Areoye, M. O. (2004) Research methodology with a statistics. Nathadex Publishers Ilorin, 128.

[4] Centre for Disease control and prevention (2006). Overweight and obesity. Retrieved March (2009) from www.cdc.gov/needphp/dnpa/obesity.

[5] Cogil, B., (2003). Anthropometric indicators measurement guide, USAID.

[6] Goon, D. T., Abel, L. T, Shaw, B. S., Amusa, I. O., Monyeki, M. A., Akinyeni, O., \& Alabi, O. (2001). Anthropometrically determined nutritional status of urban primary school children in Makurdi, Nigeria, Public Health Journal 11. 769.

[7] Hafiz, A, Ibrahim, A. Y, Atiku, M. K. (2012). Nutritional status of Adolescents from selected secondary schools in Katsina state, Nigeria. Nigeria Journal of Nutritional Sciences, 33 (2): $12-14$.

[8] Jaswal, S., Grewal, G., Vig. D, \& Gulanti, J. (2003). Anthropometric assessment of nutritional status of primary school boys 6-8 years, Punjab Journal of Human Ecology 14 (1) 63-66.

[9] Ministry of Education, Asaba (2010). Update of Student enrollment in primary school 2010.

[10] National Centre for Health and Statistics (NCHS 2000).

[11] Nwokoro, S. O., Ifeda, K., Onochei, O. \& Olomu, J. (2006). Anthropometric assessment of nutritional status and growth of $10-20$ years old individuals in Benin-City (Nigeria) metropolis. Pakistan Journal of Nutrition, 2006. 5: 117-121.

[12] Ogbe, J. O \& Ekuremu, J. (2016). Anthropometric Indices as Determinant of Health Status among primary School Children in Delta South-Senatorial District, Delta State, Nigeria. Pakistan Journal of Nutrition (in print).

[13] WHO (2000) "World Health Report" Geneva.

[14] Yunusa, I, Atiku, M. K., Abubakar, H. (2011). Socio-economic status and dietary eating habits amongst adolescents in Kano metropolis Nigeria. BEST Journal 8 (3): 217-222. 